\title{
Los inicios del astillero de la Habana en el siglo XVIII y la influencia francesa
}

\section{A emergência dos estaleiros navais de Havana no século XVIII e a influência francesa}

\section{Early Havana shipyard in the eighteenth century and the french influence}

\author{
José Manuel Serrano ALVAREZ*
}

Resumen: Este trabajo trata de establecer la influencia francesa en los inicios del astillero de La Habana durante el siglo XVIII. Aunque se ha defendido una influencia francesa muy escasa en los aspectos navales, en este trabajo se trata de mostrar cómo las ideas francesas fueron muy influyentes tanto para el ámbito general de la Marina española del siglo XVIII como para el astillero de La Habana en concreto. Las reformas francesas a nivel económico y administrativo fueron claves para entender el éxito de La Habana en el conjunto de una política naval floreciente durante el siglo XVIII, al margen de las disputas políticas propias de la monarquía española.

Palabras clave: Influencia francesa. La Habana. Política naval

Resumo: Este texto discute a influência francesa na montagem do estaleiro naval de Havana durante o século XVIII. Ainda que a influência francesa nos aspectos navais tenha sido considerada irrelevante pelos estudiosos, neste texto trata-se de mostrar como as ideias francesas foram significativas tanto, em âmbito geral, para a Marinha espanhola do século XVIII, quanto para o estaleiro de Havana, em particular. As reformas francesas em âmbito econômico e administrativo foram essenciais para se entender o êxito de Havana, no conjunto da política naval florescente durante o século XVIII, independente das disputas políticas próprias da monarquia espanhola.

Palavras-chave: Influencia francesa. Havana. Política naval

\footnotetext{
* Profesor Asociado, Departamento de Historia, Universidad de Antioquia (Colombia); Adjunct Associate Professor, History Department, Texas Tech University (EE.UU.) Recepción de correspondencia: calle 70 No. 52 - 21 | Apartado Aéreo 1226 | Dirección: calle 67 No. 53 - 108, Conmutador: [+574] 2198332 - 444 8332. E-mail: jmserranoalvarez@gmail.com
} 


\begin{abstract}
This paper endeavours to discuss French influence at the very beginnings of the rise of the Havana shipyards during the eighteenth century. Although the French influence, with regards to marine issues, has been considered to be somewhat irrelevant by scholars, this paper attempts to show how French ideas were very influential as much within the general scope of the Spanish merchant marine during the eighteenth century, as they were, more specifically, within the Havana shipyards. French reforms, in economic and administrative areas, are key to understanding Havana's success in marine policy during this time, in spite of the political disputes of the Spanish monarchy.
\end{abstract}

Keywords: French influence. Havana. Marine policy.

La situación de la marina de guerra española, y en general del estamento militar, al iniciarse el siglo XVIII era caótica. Se ha discutido mucho si anteriormente había existido verdaderamente un poder naval español. Este argumento ha sido esgrimido fundamentalmente por David Goodman, para quien la marina de guerra española en el siglo XVII ya estaba en franca decadencia y apenas podía cumplir sus funciones (GOODMAN, 2001). Aunque su tesis no carece de cierto fundamento, no cabe duda que el dominio oceánico español durante los siglos XVI y XVII atestigua lo contrario, pues de otra forma hubiera sido imposible sostener el Imperio español en América. Nunca, a lo largo del siglo XVII, se vieron completamente cortadas las comunicaciones entre Sevilla y las Américas, y el flujo de plata y productos siguió su lento y penoso transitar en ambas direcciones. Resulta innegable que durante esta centuria la marina española pasó por mayores dificultades, y que en ocasiones la carencia de buques y marinería provocó no pocos retrasos y algún que otro disgusto a la Corona. También es cierto que la potencia naval española no era con los últimos Austrias lo que había representado antaño, pero el control de los océanos se mide también por el continuado éxito en mantener unidos los diferentes territorios a ambos lados del Atlántico, y en este sentido España pudo contener a sus enemigos sin demasiados sobresaltos. La decadencia, por tanto, fue más cuantitativa que cualitativa, ya que coincidió con un momento en que ni Francia, ni Inglaterra, ni Holanda representaban serias amenazas en el mar, probablemente por sus propias disputas políticas y comerciales. En cambio, en los comienzos del siglo XVIII, no existe tal dilema interpretativo, toda vez que el poder naval español era inexistente desde un punto de vista objetivo ${ }^{1}$.

Pero, ¿qué es el poder naval? Sería interesante definirlo, toda vez que no ha existido un consenso en cuanto a su verdadera significación. Para el historiador naval militar, el poder naval representa esencialmente la capacidad de un Estado para batir a sus enemigos en las batallas que se 
vea obligado a enfrentar, así como la voluntad de desplazarlos, por vía del enfrentamiento directo, de los principales canales marítimos. Esta es la concepción del poderío naval que ha prevalecido hasta hace muy poco tiempo, en especial desde la publicación en 1890 de la obra de Alfred T. Mahan, La influencia del poder naval en la Historia. Este pensamiento anglosajón sobre lo que fue y debería ser el poder naval ha desplazado durante décadas al concepto aún más amplio que, en nuestra opinión, es más cercano a la realidad histórica. En este sentido, para el historiador no militar, el poder naval y lo que representa trasciende de lo meramente bélico y táctico, para desplazarse hacia una concepción global de todos los elementos que entran en juego en la consolidación del poder sobre los mares. El estudioso militar percibe el universo naval exclusivamente como un mecanismo final de acción directa sobre las fuerzas enemigas que se le oponen, prestando atención únicamente al éxito o fracaso del producto último. Sin embargo, olvida que tras el navío se esconden fuerzas mucho más poderosas que son las que realmente conceptúan la verdadera potencia de un Estado. Y estas fuerzas tienen que ver con el componente humano, con la técnica constructiva, con la organización financiera y con la estructura administrativa de la que surge, en última instancia, el navío de combate.

Si España comenzó el siglo XVIII con una marina de guerra casi inexistente, cabría preguntarse las causas reales más ocultas, en vez de fijarse exclusivamente en la escasa capacidad táctica de las escuadras españolas para vencer a sus enemigos en el mar. Estas causas, a nuestro entender, descansan en primera instancia en el agotamiento del modelo español de construcción naval basado en el asiento de particulares, y en último término, en la escasa implicación de todos los actores que podían haberse puesto en juego en la maquinaria de la que surgían los navíos. Aquí vamos a atender principalmente al último de los elementos, que tienen que ver directamente con la exigua, si no nula, aportación de los astilleros americanos, y en especial el de La Habana. Fue precisamente la inclusión de La Habana en la dinámica constructiva del nuevo siglo, fuertemente influenciada por el modelo francés, lo que convirtió este astillero en el núcleo central, primordial y floreciente del renacimiento del poder naval español en el siglo XVIII.

La conflagración sucesoria en la que se vio envuelta España entre 1700 y 1713 afectó decisivamente a la marina de guerra que, sencillamente, se tuvo que plegar a los designios de Francia, aliada en la contienda. Los efectivos de las diferentes armadas se reducían hacia el año 1700 a unos pocos navíos, mal preparados y pertrechados, la mayoría muy antiguos. Las tripulaciones eran escasas y los recursos dinerarios aún más cortos. Con este panorama, los astilleros cantábricos se encontraron prácticamente paralizados por falta de pedidos debido a la demora en los pagos, los incendios y los ataques enemigos ${ }^{2}$. La carencia de medios navales era tan dramática que se hizo necesario la incautación de navíos y buques de particulares imprescindibles 
para destinarlos a empresas bélicas (GARCÍA, 1983, p.7). Esta coyuntura, que se puede fijar desde la década de 1690, era también extensiva a América y sus astilleros.

La acción tutelada de la marina francesa sobre la española fue realmente humillante para los marinos españoles, pues sin las escoltas de Duccase o Chateaurenault - al menos seis viajes a América entre 1701 y 1713 - el comercio interoceánico habría quedado completamente cortado durante más de una década (BUCHET, 1999, p.5). Durante estos difíciles años de cierta anarquía administrativa e inestabilidad política en la península, el papel de La Habana decayó bruscamente, debido en gran medida a que en los astilleros americanos los mecanismos eran muy diferentes a los peninsulares.

En efecto, en las Indias operaban diversos astilleros desde hacía décadas, de los que Cartagena de Indias y La Habana eran los más importantes debido a sus posiciones geoestratégicas en el Caribe. Ambos operaban de manera diferente a como lo hacían sus iguales en la península, y tanto sus responsabilidades constructivas como sus modelos administrativos tenían poco que ver con los peninsulares. De ahí se desprendía la enorme diferencia que se visualizaba entre el astillero de La Habana, y los grandes astilleros peninsulares de El Ferrol o Cádiz.

Sin embargo, La Habana seguía siendo tan vital para la Corona como propicia a sufrir graves quebrantos en sus actividades internas. La causa principal descansaba en la dependencia de la plata mexicana y a su tradición bicentenaria, que hacía de las actividades constructivas navales una función monopolística casi exclusiva del gobernador de la plaza, con los evidentes inconvenientes. Como seguía siendo base naval indispensable para el tornaviaje, el astillero habanero nunca llegó a cerrar ni a frenar su actividad, pero las remesas de plata mexicana escasearon, y la mayoría de las que llegaban desde Veracruz eran en realidad reexpedidas a España donde eran más necesarias para la continuación de la Guerra de Sucesión.

Como se ha apuntado, uno de los principales inconvenientes era la carencia de una estructura clara en la administración de los asuntos del astillero. Tradicionalmente, habían sido los gobernadores los detentadores de todas las facultades inherentes a la maestranza, arreglo de buques, contratas y la administración financiera. Mientras que en la península la construcción naval fue durante el siglo XVII, de manera generalizada, mediante asientos privados, en La Habana este vital asunto era competencia exclusiva del gobernador. Era él quien decidía, en función de las necesidades y de las posibilidades financieras, qué se hacía en el puerto. Como consecuencia inevitable, los gobernadores cayeron en la tentación de utilizar el astillero como una posibilidad más de negocio y escalada social, ya que pronto se instauró la costumbre de conceder las contratas y asientos a las mejores familias, lo que las unía indefectiblemente con el poder. 
Aunque formalmente el astillero de La Habana constituía parte de una red más amplia de astilleros americanos, y era una de las bases de la Armada de Barlovento - teóricamente la base principal era Veracruz -, al entrar en el siglo XVIII su estatus jurídico y su papel dentro del organigrama de astilleros españoles resultaba poco claro; era un astillero más, y eso era todo, al mismo nivel que el de Guayaquil. La falta de centralización administrativa, propia de las Austrias y la carencia de una idea clara de cuál debía ser la política naval en América, dejó al astillero en una situación inestable hasta que se emprendieron los grandes procesos de reforma en la marina.

Pese a que la situación general de la marina era pésima, en La Habana no se detuvo completamente las actividades en el astillero. En 1701 el maestro mayor Joseph Ruiz de Campos recibió el encargo de construir dos galeones afragatados con un costo de 39.491 pesos (AGI Santo Domingo, 417, carta de 9 de noviembre de 1701). En realidad estos encargos constituían, desde el punto de vista técnico, el paso previo hacia la construcción de navíos de línea, pues el galeón, como unidad de combate, había dejado de ser operativo desde finales del siglo XVII, y aunque se construyeron algunos en España en los primeros años del nuevo siglo, la tecnología naval, muy influida por la moda francesa, introdujo decisivamente los nuevos modelos. Así, entre 1700 y 1702 salieron del astillero de La Habana los navíos Santa Rosa y Rubí que serían los últimos modelos híbridos pero también los últimos buques que saldrían del arsenal habanero en más de diez años ${ }^{3}$.

La influencia francesa en estos años fue decisiva tanto para la revitalización de la Armada española como para el astillero habanero. Teniendo presente la necesidad de canalizar y centralizar los recursos económicos como un primer paso hacia la modernización de la Marina, tanto Felipe $\mathrm{V}$ como su pléyade de colaboradores franceses distinguieron inmediatamente la necesidad de implementar el modelo francés que había resultado exitoso en las últimas décadas. Así fue como en 1705 se creó la Junta de Restablecimiento del Comercio con el fin de poner orden a los asuntos del comercio con Indias al tiempo que se trataba de implementar ventajas para los franceses (GARCÍA, 1989, p.212). Éstos estaban fuertemente interesados en influir en los asuntos navales como un medio eficaz y directo de aprovecharse de la debilidad española en América, rompiendo así su consabido monopolio comercial. Esta Junta trató de incluir las incipientes reformas de la marina con los asuntos de Indias, máxime si se tiene en cuenta el carácter instrumental que jugaba la Armada en la defensa de los intereses comerciales atlánticos ${ }^{4}(\operatorname{SOLANA}, 1996$, p.66). Los inspiradores de esta Junta fueron los franceses Nicolás Mesnager y Ambrosio Daubenton ${ }^{5}$, éste último muy cercano a Jean Orry quien, como consejero de Felipe V, había llegado a España en 1701 para poner orden a las finanzas militares de la monarquía hispana. La concatenación de hechos (y la innegable posición de privilegio que tenía la poderosa Francia frente a la debilitada España), llevó al nombramiento de Daubenton como Intendente de Marina el 6 de junio de 1705. Esta 
institución, de amplia tradición en Francia, constituía la primera medida de choque para aliviar la desorganización de la Marina y suponía la imbricación de un modelo desconocido hasta entonces en el universo naval hispano.

No fue, por tanto, causalidad que el 5 de junio de 1705 se nombrara como primer Intendente de Marina de España a Ambrosio Daubentón, que tenía no sólo la confianza del poderoso e influyente Juan Orry, dos veces Ministro de Hacienda con Felipe V, sino que además era hermano del sacerdote Guillermo Daubentón, jesuita francés confesor del monarca y con una muy notable influencia sobre el primer Borbón español (ALONSO, 1992, p.299). Las facultades del Intendente de marina fueron decisivas para el futuro de la Marina de guerra española en el siglo XVIII, pues dio coherencia a la institución militar y centralizó eficientemente todos los recursos que eran indispensables para hacer frente a la creciente amenaza inglesa tras Utrecht. El intendente ejercía jurisdicción civil, criminal, política y económica para entender y conocer, en nombre del Rey, todas las causas judiciales y extrajudiciales de los dependientes del Ministerio, como eran los Comisarios Ordenadores y de Guerra. También eran responsables de los capitanes de Maestranza, empleados de arsenales de Marina, almacenes, maestros de jarcia y víveres, y de los sirvientes asentistas. En orden a las construcciones navales era el máximo responsable de examinar los recursos, materiales y dinerarios, disponiendo la forma adecuada para que no se detuvieran las obras una vez comenzadas. ${ }^{6}$ Siendo Secretario de Estado y del Despacho de Marina e Indias Bernardo Tinajero se produjo la tan esperada creación de la Marina de guerra española en el siglo XVIII, mediante la supresión de todas las armadas existentes en 1714 y la centralización de todos los buques de guerra en torno a un solo ministerio y a un solo Intendente General de Marina (TOMÁS, 1998, p.389). La creación formal por Tinajero de la moderna Armada española del siglo XVIII venía a completar la influencia francesa, máxime teniendo en cuenta que las amistades de Orry con el Secretario eran muy conocidas. El hecho de que muchos de los ministros españoles odiaran a Orry no es sino una prueba del innegable influjo ejercido por el francés. El inveterado conservadurismo de los españoles y su tradicional apego al sistema de Consejos fue un factor decisivo en este odio hacia Orry y sus reformas, pero no evitó en absoluto que la planta administrativa y financiera de la nueva España llevara el indeleble sello francés. Huelga decir que las intrigas palaciegas en torno a la relación de Orry con la princesa de los Ursinos fueron un acicate más para el ataque contra el francés, cuya independencia política era muy mal soportada por los españoles. Ahora bien, la enemistad personal contra Orry obedecía más a las envidias personales y rivalidades políticas que a una resistencia burocrática a las reformas de cuño francés, y esto se percibió muy bien en los resultados prácticos vislumbrados entre 1700 y 1720. 
¿Cómo influyó esta influencia naval francesa en el astillero de La Habana? Muchos de los hombres que tuvieron un impacto directo en las reformas de la Marina tenían formación americana. Bernardo Tinajero, José del Campillo, Andrés de Pes o Julián de Arriaga (todos ellos mentores de la nueva marina a lo francés) habían realizado carrera administrativa-política en América o conocían de primera mano los asuntos navales indianos. Andrés de Pes, curtido marino que conocía perfectamente las bondades de los astilleros americanos, y cuya amistad con Daubenton era conocida, se había hecho eco de los proyectos de construcción y revitalización de los astilleros americanos, algunas de cuyas propuestas manejó directamente. Junto con el proyecto inicial de Andrés de Arriola del año 1713 para concentrar la construcción naval en La Habana, se había manejado también la posibilidad de que fuese la Jagua (también en Cuba) y Coatzacoalcos los elegidos en América (NAVARRO, 1989, p.119). Andrés de Pes sopesó las propuestas y acabó eligiendo a La Habana como el más factible. Su posición como Secretario de Marina fue decisiva, así como su conocimiento directo de La Habana y sus amistades pro-francesas.

En efecto, en 1721 fue nombrado nuevo Secretario de Marina e Indias Andrés de Pes, sucediendo a Miguel Fernández Durán, titular de este ministerio desde 1719 que, aunque continuó con las medidas emprendidas por Tinajero, no tuvo la suficiente iniciativa para impulsarlas. Andrés de Pes tenía, en cambio, una extraordinaria capacidad de trabajo y una iniciativa tal vez sólo equiparable a la que tendría, años más tarde, Patiño al frente del mismo ministerio. Tenía una excelente formación marinera, habiendo participado como general de flotas en dos importantes arribadas a España en 1707 y 1710 procedente de América. Fue nombrado incluso para dirigir el bloqueo de Barcelona en 1714 y gozaba de una gran conocimiento de La Habana y su astillero. De hecho, en 1719, siendo miembro del Consejo de Indias, se permitió atacar rudamente el nuevo reglamento par la guarnición de La Habana por considerarlo inapropiado ${ }^{7}$, y no hay que olvidar que había participado en importantes reuniones de la Juntas de Marina junto con Patiño y Alberoni donde se decidieron vitales cambios en el organigrama de la Armada y en el papel de La Habana en el seno de la nueva política naval española. Según el propio Patiño, participó en la toma de decisiones que abocaron en el establecimiento del estanco del tabaco en La Habana en 1717 y en la ordenación y apresto de buques destinados allí (PERONA, op. cit. p.78). Lamentablemente su muerte en 1723 cercenó parcialmente la rápida ascensión del poderío naval español, aunque las bases eran tan sólidas que ya no tendría vuelta atrás.

La decisión de establecer en La Habana el astillero más importante de América obedeció a tanto a las presiones desde las élites habaneras (cuyos beneficios eran obvios y no podían dejar escapar), como a la idea, típicamente francesa, de concentrar en un solo lugar todo lo referente a la construcción naval. Hasta ese momento, la tradición española había descentralizado los diferentes 
componentes que tenían relación directa con el universo constructivo naval. Fue típico del siglo XVII español que las fundiciones, maderas, velamen y estructuras contractuales que operaban sobre la construcción de un navío estuvieran dispersas. No era extraño que los diversos componentes del buque procedieran de lugares muy diferentes, obedeciendo a una política asentista mal planificada, y sobre la que operaban intereses particulares. Los astilleros franceses, antes y después de Colbert, concentraban todo lo referente a la construcción en los alrededores del astillero elegido, incluyendo la planta de árboles cercanos para ahorrar costos. Toda una industria naval surgía, por consiguiente, alrededor del puerto y su astillero. Esta idea fue trasladada, a través de los personajes ya mencionados, a La Habana, y fue decisiva en el florecimiento de los astillleros peninsulares que, como La Carraca en Cádiz, se convirtieron pronto en modelos de construcción navales.

La implementación de la influencia francesa en La Habana tenía ya claros precedentes. Al menos desde finales del siglo XVII se había iniciado una tendencia en Cuba para concentrar los recursos financieros que llegaban de Nueva España, distribuyendo los caudales de manera separada para el astillero habanero y las fuerzas militares terrestres. Esto determinó que hacia 1710 el astillero cubano se convirtiera en lugar permanente de construcción naval para la España del siglo XVIII gracias a la acertada previsión administrativa y política de los gobernadores de la isla y sus relaciones con los virreyes de Nueva España, algunos de los cuales, como el marqués de Casafuerte, mantuvieron una nutrida correspondencia con Andrés de Pes para concentrar en La Habana todo lo referente a la construcción naval (BAEZA, 2005, p. 881-882). Aunque ya se ha visto que la actividad constructiva nunca había desaparecido totalmente, y que la tradición era secular, en 1710 el alcalde ordinario de La Habana, Agustín de Arriola, cuya familia hacía décadas que influía decisivamente en los designios de la ciudad a través de los cargos en el cabildo, propuso a Bernardo Tinajero la conversión del astillero en definitivo ${ }^{8}$. El proyecto fue finalmente aprobado contando con la aquiescencia del constructor naval Antonio Gaztañeta y del propio José de Grimaldo, decisión que se percibe en el documento de 15 de enero de 1713 en el que Tinajero argumentó con solidez a Grimaldo las ventajas del establecimiento en Cuba de un astillero poderoso y organizado modernamente.

Por otra parte, la presencia en La Habana de José del Campillo y Cossio entre 1719 y 1725 como Comisario de Guerra de Marina acabó siendo providencial ${ }^{9}$. El futuro Ministro de Marina, que sin duda conocía bien la potencialidad de La Habana, y estaba fuertemente imbuido de la idea francesa de concentración administrativa, inició la construcción de dicho astillero en 1722 cerca del castillo de La Fuerza, intramuros de la ciudad (ORTEGA, op. cit. p. 39). En 1724, siendo capitán de la maestranza Juan de Acosta, personaje decisivo en la historia del arsenal habanero, se inauguró formalmente con la botadura del navío San Juan, de 50 cañones. Antes de esa fecha habían salido 
de La Habana los siguientes otros navíos: Santa Rosa (1700), Rubí (1701), San Francisco (1714), San Juan Bautista (1718), Victoria (1718), Príncipe de Asturias (1720), Conquistador (1723) y San Juan Bautista (1724) ${ }^{10}$.

Antes de 1715 apenas se contaba con una veintena de buques en las diferentes armadas españolas, ninguno de los cuales era navío de línea, lo que demostraba el completo fracaso de la política naval del siglo XVII (OZANAM, 1981, p.457). La reorientación de la política española tras la llegada del primer Borbón, Felipe V, con unas miras más puestas en América que en Europa, supuso los inicios del resurgimiento del poderío naval español, auspiciado, como se ha visto, por el componente francés. El Secretario del Consejo de Indias, Bernardo Tinajero de la Escalera, había comprendido la necesidad de reforzar el papel de España en el mar como medida inmediata para tratar de paliar los efectos negativos que sobre el comercio tendría en el futuro el Tratado de Utrecht de 1713. El objetivo prioritario era restablecer un programa constructivo netamente español, que pudiera independizarlo de la necesidad que en aquel momento se tenía de recibir escolta naval de los franceses cada vez que una flota americana se planteaba su regreso a la metrópoli. Eso no evitó que, pese a la idea de españolidad, y ante el fracaso de la antigua manera española de canalizar los recursos de la Marina, se decidiera implementar el modelo francés en España y las Indias. Para ello, se contó tanto con los astilleros españoles como con los americanos, pero Tinajero dejó claro sus preferencias sobre éstos últimos al decir que "si el navío fabricado en Vizcaya durase, que se duda, diez años, el de Indias pasará de treinta” (MERINO, 1981, p.97). Adoptando los diseños del constructor Antonio de Gaztañeta firmó primeramente en 1713 un asiento privado con Manuel López Pintado para la construcción en La Habana de diez navíos y ese mismo año, en junio, se aprobó un proyecto para elegir al habanero como el astillero por excelencia de América. El extenso informe, de unas 100 caras de folio, sopesaba con detenimiento los diferentes astilleros americanos, sus ventajas e inconvenientes, así como el panorama general de la armada española y sus objetivos en la nueva lucha que se presentaba ${ }^{11}$.

Este informe, que ha pasado bastante desapercibido a los historiadores navales, constituye uno de los puntos culminantes de las reformas de la marina en los tiempos de Felipe V. Aunque se ha resaltado, no sin razón, la evidente importancia de los decretos unificadores de la Armada de 1714, se suele pasar por alto que, siendo La Habana el principal astillero español y el único que estuvo permanentemente en activo durante más de cien años, es imprescindible averiguar el origen de su creciente importancia entre los astilleros hispanos ${ }^{12}$. Es cierto que el plan original de Tinajero venía unido a determinadas actuaciones puntuales, como las del asentista López Pintado, y que finalmente no se pudo concretar el transporte de materia a América para el inicio de la construcción debido a que el esfuerzo bélico se trasladó en último momento al sitio de Barcelona ${ }^{13}$. También es 
cierto que el favorito de Felipe, Jean Orry, al regresar de Francia vetó el programa de Tinajero en favor de la compra de navíos a los franceses (INGLIS, 1985, p.48). Este último punto indica claramente que mientras Orry y los franceses ocupaban el poder en Madrid, controlaban los designios de la Marina tratando de implementar el modelo francés al tiempo que obtenían ventajas comerciales. La defenestración en 1715 de Orry no suponía una modificación del modelo centralizador francés, sino más bien el triunfo de los españoles por hacerse con el control directo del mismo. En el centro de la cuestión no estaba si era válido a no una Marina que imitara a la del país galo, sino si este plan debía ser controlado por los españoles una vez que hubiera demostrado su validez. La egolatría de Orry fue lo que le llevó a negar a los españoles que se pusiera efectivamente en marcha un plan general que había nacido de él mismo y de sus colaboradores franceses. Sin embargo, y pese al mal disimulado enfado de Orry, La Habana se concretó de facto como el único astillero verdaderamente activo de América, y a larga, triunfó la tesis última de Tinajero quien, efectivamente, buscaba fijar en La Habana el centro de la construcción naval de la naciente nueva Armada española.

La Habana se encontró pronto en el epicentro de las construcciones navales que con gran fuerza se incentivaban desde España. No eran desconocidas en España las cualidades, dureza y buenos portes de los navíos allí construidos. La madera americana tenía una enorme fama y en determinadas latitudes era abundante y de fácil acceso. Los astilleros españoles esperaban con avidez la llegada de estas maderas para sus propias construcciones y arreglos. Así, cuando se pensó en el lugar definitivo para iniciar el ambicioso programa constructivo las dudas quedaron rápidamente despejadas a favor de La Habana ${ }^{14}$. Esta elección quedó rápidamente confirmada, como se ha indicado, al encargarse por Real Cédula de 26 de agosto de 1713 a Manuel López Pintado la construcción en La Habana de 10 navíos y 2 pataches ${ }^{15}$, siguiendo los navíos los diseños de Gaztañeta que privilegiaban los portes de 60 cañones y no llegaban a las 1.000 toneladas de desplazamiento. Estas construcciones serían sufragadas por partidas especiales provenientes de México y destinadas en exclusiva al astillero habanero aunque fiscalizadas en todo momento por el tesorero real. Al mismo tiempo se prohibía expresamente la construcción por parte de particulares de navíos de ningún tipo, lo que equivalía en la práctica a un control monopolístico de la Corona del astillero habanero en tanto continuaran las construcciones encargadas a López Pintado o se resolviera cambio al respecto. Esta dinámica administrativa y de fiscalización encajaba muy bien con el modelo de Intendencia francesa, priorizando la conjunción de intereses generales a la anterior etapa en la que la multiplicidad de asentistas privados ligados a intereses poco claros habían provocado un colapso completo de la Armada. Ahora, se implementaba un control tanto vertical como horizontal, en las que cualidades como el conocimiento técnico y administrativo, los 
contactos locales y el rigor en la fiscalización y optimización de los recursos, tenían una semejanza más que evidente con la de los arsenales franceses.

Sin embargo, ja elección de La Habana no estuvo exenta de problemas ya que el negocio de la construcción naval era un bien que no pocos puertos americanos se disputaban. Aunque el informe de Tinajero de 1713 dejaba bien evidentes las ventajas de la isla de Cuba, en 1720 llegó a la Corte un plan del entonces gobernador de Guatemala Francisco Guiral para trasladar a Coatzacoalcos (MASSIEU, 1958, p.373) el arsenal más importante de América, con muchas y muy evidentes ventajas, en apariencia ${ }^{16}$. Aparte de los ahorros que se prometían se estimaban como mejores las maderas locales, antes incluso que las habaneras. El proyecto, aunque se cursó al Secretario de Marina, no prosperó, sin duda por la mayor y más larga tradición local en Cuba, y a los no menos importantes intereses que prevalecían en la isla, muchos de los cuales estaban fuertemente entroncados en la Península. No es baladí que algunos de los que hicieron posible el nacimiento del moderno astillero en La Habana y su posterior despegue, hubieran estado durante años en la isla sirviendo a los intereses del Rey ${ }^{17}$.

Uno de los que con más ahínco defendió el proyecto habanero fue el propio Jerónimo de Uztáriz quien en 1724 escribió lo siguiente refiriéndose al puerto cubano:

[...] el Astillero más seguro, cómodo y más a la mano para la construcción y para el avío y ocupación de los nuevos navíos, es el de La Habana, con el considerable beneficio de que si los fabricados en Europa durante de 12 a 15 años, se conservan más de 30 los que se hacen allá con el cedro, roble más duro y otras maderas de superior firmeza y resistencia; lo que es causa también de que necesitan de menos carenas y de otros reparos.

Fuera de que en un combate tiene también el cedro la ventaja de que embebe en si las balas, sin que se experimenten los efectos de los astillazos, que en los navíos fabricados en Europa, y que suelen maltratar y aun matar mucha gente. Pero es de advertir también que si en España se cuidasen los navíos armados y desarmados, como en Inglaterra y Holanda durarían duplicado tiempo.

[...] Mucho convendrá al servicio de SM. y al bien de sus barcos que todos los navíos que se hubiesen de emplear, así a la guardia de las Flotas y Galeones como en la Escuadra de Barlovento y otros mares de Indias, sean construidos de maderas de aquellas provincias y en sus astilleros [...] (UZTÁRIZ, 1968, p.216-217).

Las ideas prohabaneras de Uztáriz son otro fiel reflejo de la influencia francesa y constituían uno de los exponentes más firmes en España de la defensa del modelo francés. De hecho, Ustáriz era un firme defensor del modelo triunfante del poderoso ministro francés Choiseul, para quien el engrandecimiento de un país pasaba indefectiblemente por el fortalecimiento del comercio y la marina de guerra (LÓPEZ, 2005, p.96). Por tal motivo, no resultaba extraño que el papel de La Habana ganara enteros de una manera tan rápida y eficaz; allá se concentraban todos los elementos 
que hacían posible ambos aspectos del eje que articulaba un aumento del poder naval español: el comercio y la marina de guerra.

En este sentido, la actitud de Patiño, primero como intendente de marina y después secretario de Marina e Indias, 1726-1736, marcó el inicio de la recuperación del poder naval español y el lento resucitar del proyecto de Tinajero y las ideas de Ustáriz. Además de proceder a una completa reestructuración administrativa y económica de la Armada, Patiño se fijó como elemento primordial la construcción naval, y para ello no dejó de continuar el modelo típicamente francés de concentración fiscal de los recursos navales. En este sentido el papel habanero se vio claramente favorecido por el agresivo programa constructivo, especialmente desde que se hizo cargo del ministerio.

A pesar de que las primeras disposiciones orientadas a la formación de una marina de guerra comenzaron en 1714 con la unificación de las distintas flotas y el nombramiento de Bernardo Tinajero de la Escalera como Secretario de Marina e Indias, podemos considerar que el auténtico artífice de la moderna Armada española fue José Patiño, designado Intendente General de Marina en 1717. Patiño comprendió tanto la necesidad de construir buques con un cometido específicamente bélico, como de profesionalizar el personal que los había de dirigir. En este sentido, uno de sus objetivos preferentes fue la formación de los futuros oficiales, para lo que recabó informes sobre los métodos de enseñanza seguidos en las academias navales de otros países. La estructuración de la Academia española estaría más próxima al modelo francés que al inglés, aunque ninguno de los dos satisfacía plenamente a Patiño ${ }^{18}$.

Siguiendo, por tanto, los planes elaborados por Alberoni, en 1717, se creó el cargo de Intendente General de Marina (figura típicamente francesa), cuyo titular, José Patiño, ${ }^{19}$ acabaría siendo el verdadero padre de la moderna armada de guerra española ${ }^{20}$. En febrero del mismo año se reorganizaron las brigadas de artillería y los batallones de Marina en un notorio intento de profesionalizar esta arma (MERINO, 1981, p.98-99), y en abril se reglamentaba el cuerpo de oficiales de guerra a la vez que se creaba la compañía de guardias marinas. El cuerpo administrativo de la Armada lo organizó Patiño también a finales de abril en medio de una frenética actividad burocrática que estaba poniendo en pie en muy poco tiempo los cimientos de una Armada moderna y poderosa. La Compañía de Guardias Marinas tuvo su sede en el Castillo de la Villa de Cádiz. La primera disposición que reguló sus actividades fue la Instrucción para el gobierno, educación, enseñanza y servicio de los Guardias Marinas, y obligación de sus Oficiales y Maestros de facultades, de 15 de abril de 1718. En ella se mencionaba explícitamente la necesidad de la formación científica para todo buen oficial de marina ${ }^{21}$. 
Los requisitos que debía reunir un aspirante a guardiamarina, según indicaba la Instrucción de Patiño, eran los siguientes: ser hijo de hidalgo o de militar con empleo de capitán o superior, tener una edad comprendida entre 14 y 16 años y saber leer y escribir. Es interesante subrayar que la corona encontró en la nobleza baja un importante apoyo para sus proyectos, pues los miembros de este estamento utilizaron el ejército, la marina y la administración estatal, para lograr una consideración social que se les negaba por nacimiento. Por el contrario, las nuevas vías de acceso a la profesión militar encontraron ciertas reticencias por parte de la nobleza alta, que prefería el antiguo sistema de ascensos, en el que apenas se valoraban las cualidades militares.

Todos estos avatares políticos y reformas en la marina afectaron, obviamente a La Habana, que tras su configuración como el astillero americano por excelencia, pudo iniciar en la década de 1720, de la mano de las actitudes políticas tan favorables, el despegue definitivo. Hubo un último intento de desplazar, o al menos compartir, la incipiente primacía de La Habana en cuanto a la fábrica de bajeles. En 1726, el General de la Armada Antonio Serrano, encontrándose en La Habana, escribió a José Patiño, ya como Secretario de Marina ${ }^{22}$, con la idea de que tal vez podría fabricarse los cuatro bajeles que el rey había ordenado fabricar en La Habana en los astilleros de Coatzacoalcos, e incluso consideraba posible hacer navíos de 80 cañones en Pensacola. Lógicamente estos intentos cayeron en saco roto, pero La Habana siempre contó con el astillero guatemalteco como un duro competidor a lo largo de todo el siglo. De hecho, muchas de las arboladuras para los navíos mayores llegaron desde las costas continentales, ya que al parecer este tipo era más resistente que el cubano.

Mientras tanto se botaba en 1725 el San Lorenzo, de 50 cañones y al año siguiente el San Jerónimo, del mismo porte, ambos concluidos por el constructor Juan de Acosta, quien ya había tenido duras disputas con los ganaderos locales por el asunto del corte de maderas (MARRENO, 1972, p.4). Aunque estas disputas se prolongarían durante todo el siglo XVIII lo cierto es que la Corona había dejado bien claro que la prioridad la tenía, en ese momento, la construcción naval. Los desesperados intentos de los ganaderos y hacendados eran obvios y lógicos en una situación de claro intrusismo de las autoridades locales sobre unas prácticas, el corte de maderas, que tradicionalmente había sido libre en La Habana. Sin embargo, la moderna configuración del astillero, y la creación de puestos burocráticos oficiales y fiscalizados por el gobernador y en última instancia por el Ministro de Marina, como era el caso de Comisario de Marina, dejaban pocas posibilidades a los siempre quejosos hacendados.

El problema principal para el astillero era, y fue a lo largo de todo el siglo, la financiación. Con independencia del tipo de construcción, bien por asiento o por administración, La Habana no disponía de recursos propios capaces de sacar adelante un muy ambicioso programa constructivo. 
Sus recursos locales estaban limitados y en las primeras décadas del siglo XVIII la prioridad la tuvieron las fortificaciones y la guarnición fija. Desde muy temprano se reglamentó para que los fondos fueran llegando conforme hacían falta de Nueva España, y para este fin se habían publicado ya varias reales órdenes dirigidas al virrey. En 1702 llegaron 115.000 pesos para poner en marcha la fábrica de bajeles $^{23}$ y no se volvió a enviar ninguna cantidad más hasta 1714, cuando se suministraron 20.000 pesos para la construcción naval24 ${ }^{24}$ Esta demora fue causada por la difícil coyuntura internacional que, en plena Guerra de Sucesión, y sin buques capaces de resguardar el trayecto Veracruz-La Habana por el peligro de las flotas inglesas, convertía a Cuba en una isla prácticamente sitiada.

A partir de 1725 la situación cambió notablemente, aunque no la problemática. Con la creación del astillero y los incesantes pedidos de nuevos navíos desde España la contabilidad de La Habana mostró un cambio notable, al crearse una Caja especial destinada a los envíos provenientes de Nueva España. Así, y desde ese momento, los contadores tenían que incluir en dicha caja todo el dinero mexicano desligándolo completamente del que entraba en la Tesorería principal. La Maestranza dispuso, por consiguiente, de sus propios contables y de su propia fiscalidad, y la misión principal del Comisario de Marina, y posteriormente del Intendente, consistiría en velar porque el dinero destinado a la fábrica de bajeles fuese destinado a esta tesorería propia y gastada exclusivamente en los navíos y su aderezo. En este sentido, en 1725 y 1726 ingresaron en dicha tesorería de marina 153.252 pesos y 116.179 pesos respectivamente que estuvieron fiscalizados por el Comisario de Marina José del Campillo, justo antes de que dejara La Habana para encargarse del no menos importante astillero de Guarnizo. En ese último año llegaron también, de manera extraordinaria, otros 265.365 pesos para el resguardo de la flota de Antonio Serrano y Rodrigo de Torres, pronta a partir hacia España ${ }^{25}$.

Las cuentas de esta tesorería muestran por primera vez los gastos de la fábrica de bajeles que ascendieron en 1725 a 118.879 pesos y en 1726 a 90.427 pesos $^{26}$, año este último que acabó con la construcción del navío Incendio, de 58 cañones. Los costos de estos navíos habían rondado los 45.000 pesos la unidad, y estuvieron siempre bajo la dirección técnica de Juan de Acosta, que había sido el máximo exponente de la fábrica de navíos criollos siguiendo planteamientos un poco diferentes. Aunque formalmente se seguía el modelo implantado por Gaztañeta, Acosta gozó de bastante libertad de acción, e introdujo no pocas variaciones en sus modelos.

El nombramiento en 1726 como Ministro de Marina e Indias de José Patiño, que acumularía hasta 1736 también las Secretarías de Hacienda, Guerra y Estado, abriría una nueva etapa para la marina de guerra en España y también en La Habana, que además, aquí, vendría caracterizada por la llegada de un nuevo Comisario de Marina, Juan Pinto, pronto enfrentado al insigne Juan de Acosta. 
Resulta obvio que todo el primer tercio del siglo XVIII tuvo claros indicios de una modificación completa del modelo naval español, y resulta patente que ni por tradición ni por interés político, estos cambios se generaban en el interior de la península. La actitud de los españoles fue clara a este respecto. Por una parte, necesitando de un aumento significativo de su capacidad naval ante el peligro real de los ingleses, vieron el modelo francés coyunturalmente aceptable a sus intereses inmediatos. Es cierto que la implementación de las ideas francesas no estuvo exenta de problemas y dificultades, pero cabe más analizarlas en clave de intereses y egoísmos políticos, que en una resistencia hacia un modelo que había dado claras muestras de eficacia. Por otra parte, una vez que la mayor parte de estas ideas se pusieron en marcha, los españoles trataron de sacudirse el poder directo que los franceses tenían sobre la política española, en especial durante los primeros quince años del siglo XVIII. Esta resistencia no supuso un intento de modificar el sistema, sino una lucha para hacerse con el control del mismo. El orgullo español sin duda se encontraba herido ante la idea de que su tradicional vecino y rival se inmiscuyera más de lo razonable en la política naval y comercial española.

En este sentido La Habana jugó un papel decisivo y en cierta forma modélico. Por una parte, se encontraba muy lejos de la península, y por tanto ajeno a las disputas de la corte entre franceses y españoles, así como por los diversos bandos en cuestión. La españolidad de la isla quedaba, por consiguiente, a salvo, y era esa una característica enormemente positiva que le situaba en una posición de privilegio para iniciar un modelo diferente sin el control o fiscalización directo de los franceses. Así, La Habana fue el primer lugar donde se instauró, de facto, el sistema de construcción mediante comisarios de marina e intendentes, pese a que ambas figuras tardarían algunos años en ser legalmente constituidas. No importaba actuar a la manera francesa sin que todos los elementos constitutivos del modelo estuvieran ya configurados. Lo esencial era dar un giro a la política naval que pusiera las bases de una Armada floreciente y poderosa, al margen de las ya clásicas disputas palaciegas. La Habana tenía todo para el éxito: posición geográfica, cercanía a las fuentes de financiación, una poderosa oligarquía interesada en el negocio naval y una administración militar habituada al control piramidal. Todos estos fueron elementos decisivos que constituyeron en La Habana un fiel reflejo del triunfo del modelo francés de intendencia sobre una estructura española habituada a la ley y el orden.

\section{Notas}

\footnotetext{
${ }^{1}$ Roger Messegué, “¿Existió un poder naval hispánico? La reciente historiografía sobre la marina en tiempos de los
} Habsburgo (1516-1659)” Revista de Historia Naval, nº 91, 1999, págs. 1-15. 
${ }^{2}$ Cruz Apestegui, “Arquitectura y construcción navales en la España Atlántica, el siglo XVII y la primera mitad del XVIII. Una nueva sistematización”, International Symposium on Archaeology of Medieval and Modern ships of Iberian-Atlantic Tradition, 2000, pág170.

${ }^{3}$ VV.AA, El buque en la Armada Española, Madrid, Museo Naval, 1981, pág. 415.

${ }^{4}$ Ana Crespo Solana, La Casa de la Contratación y la Intendencia General de la Marina en Cádiz, 1717-1730, Cádiz, Universidad de Cádiz, 1996, pág. 66.

${ }^{5}$ Nicolás Mesnager y Ambrosio Daubenton, colaboradores del ministro francés de Comercio y Marina, Jerôme de Pontchartrain, tenían experiencia en el comercio americano y habían sido enviados a España para formar parte de la Junta de Restablecimiento del Comercio en la que debían reforzar la posición francesa, María Daubot Monroy, op. Cit. Pág. 43.

${ }^{6}$ Ibídem, págs. 300-301.

${ }^{7}$ AGI, Santo Domingo, 2104A, informe de Andrés de Pes sobre el reglamento de La habana.

${ }^{8}$ El origen del astillero habanero remontado a la idea e interés de Arriola aparece citado en varios autores, entre otros, Luis Navarro García, Antonio Bethencourt Massieu y Leví Marrero.

${ }^{9}$ Nombramiento de Comisario de 1 de marzo de 1719, Dionisio A. Perona, op. cit. pág. 394.

${ }^{10}$ Existen varias listas de navíos construidos en La Habana en el siglo XVIII y en todas hay discrepancias en los nombres y años hasta la segunda mitad de la década de 1720, cuando la unanimidad es la tónica general. Los nombres que uso aquí están cotejados con las fuentes de Archivo y las listas que aparecen en John D. Harbron, Trafalgar and the spanish navy, London, Conway Maritime Press, 1988, pág. 52; VV.AA, El buque en la Armada Española, Madrid, Museo Naval, 1981, págs. 415-416 y Ovidio Ortega Pereyra, El Real Arsenal de La Habana, La Habana, Editorial Letras Cubanas, 1998, págs. 84-86, siendo las dos últimas las que me parecen más acertadas.

11 Bernardo Tinajero a José de Grimaldo, 15 de enero de 1713, AGI Indiferente, leg. 2644. Este proyecto no ha sido analizado con toda la profundidad que merece.

${ }^{12}$ Hugo O’Donnell, “La marina durante el primer reinado de Felipe V (1700-1724)”, La Guerra de Sucesión en España y América: X Jornadas Nacionales de Historia Militar, Sevilla, Deimos, 2000, p. 446. Este autor considera la unificación de la Armada y la creación de la escuela naval militar de 1717 como los dos grandes logros del reinado de Felipe V.

13 Pablo Emilio Pérez-Mallaina Bueno, La política naval en el Atlántico, 1700-1715, Sevilla, Escuela de Estudios Hispanoamericanos, 1982, pp. 405 y ss. Este autor considera un completo fracaso el plan de Tinajero.

${ }^{14}$ Véase a este respecto el excelente y voluminoso informe elaborado por Bernardo Tinajero el 15 de enero de 1713 y enviado al ministro José Grimaldo, donde se decidió la ubicación del astillero de La Habana y gran parte de la política naval de las décadas siguientes, Archivo General de Indias (AGI), México, 2045A. Ver también, Allan Kuethe y José Manuel Serrano "El astillero de La Habana y Trafalgar", XIV Congreso de la Asociación AHILA, Hispanoasia, (15211898), Castellón, 2005.

${ }^{15}$ AGI, Santo Domingo, 482. Cédula de la fecha, Leví Marrero, Cuba: Economía y sociedad, Madrid, Playor, 1972, vol. 11. Pág. 4.

${ }^{16}$ Archivo General de Simancas (AGS), Secretaría de Marina 303, informe sin fecha exacta pero datado en 1720.

${ }^{17}$ Andrés de Pes y José del Campillo son probablemente los más conocidos.

${ }^{18}$ En 1683 se crearon compañías de guardias marinas en cada uno de los tres puertos militares franceses: Brest, Rochefort y Tolón. Las enseñanzas científicas impartidas consistían en aritmética y geometría elementales, resumen de la esfera, uso de instrumentos astronómicos, fortificación, hidrografía, así como enseñanzas prácticas de tiro y construcción de buques. Véase: R. Hahn, "L'enseignement scientifique des gardes de la Marine au XVIIIe) siècle", en R. Taton (ed.), Enseignement et diffusion des sciences en France au dix- huitieme siècle, París, Hermann, 1964, pág. 547.

${ }^{19}$ Nombramiento con fecha 28 de enero de 1717.

${ }^{20}$ José Manuel Serrano, Fortificaciones..., pág. 71.

${ }^{21}$ Para una información más detallada sobre la enseñanza naval en la Armada española del siglo XVIII y la Compañía de Guardias Marinas de Cádiz, pueden consultarse los siguientes trabajos: J.F. Guillén Tato, "La enseñanza naval en España". Revista General de Marina, 83 (1918), pág. 605-627; 84 (1919), pág. 49-64, 179-196; A. Lafuente y J.L. Peset, "Militarización de las actividades científicas en la España ilustrada (1726-1754)", J.L. Peset et al., La Ciencia moderna y el nuevo mundo, Madrid, C.S.I.C., 1985, págs. 127-147; A. Lafuente y M. A. Sellés, "El proceso de institucionalización de la Academia de Guardiamarinas de Cádiz. (1717-1748)", Actas del III Congreso de la Sociedad Española de Historia de las Ciencias, San Sebastián- Zaragoza, Sociedad Española de Historia de las Ciencias, 3 vols., 1986, Tomo 2, págs. 153-175; A. Lafuente y M. A. Sellés, El Observatorio de Cádiz (1753-1831), Madrid, Instituto de Historia y Cultura Naval, 1988.

${ }^{22}$ Su nombramiento como Secretario de Marina e Indias tiene fecha de 21 de mayo de 1726.

${ }^{23}$ AGI Contaduría, 1152, Cuentas de Real Hacienda.

${ }^{24}$ AGI Contaduría, 1153, Cuentas de Real Hacienda.

${ }^{25}$ AGI Contaduría, 1154, Cuentas de Real Hacienda. 
${ }^{26}$ AGI Contaduría, 1154, Cuentas de Real Hacienda.

\section{Referências}

ALONSO, A. R. Historia de la Administración y fiscalización económica de las Fuerzas Armadas, Madrid, Ministerio de Defensa, 1992, p.299.

APESTEGUI, C. Arquitectura y construcción navales en la España Atlántica, el siglo XVII y la primera mitad del XVIII. Una nueva sistematización. International Symposium on Archaeology of Medieval and Modern ships of Iberian-Atlantic Tradition, 2000, p.170.

BAEZA, A. Fundición de artillería en Nueva España. Estudios sobre América, siglo XVI-XX, Sevilla, Escuela de Estudios Americanos, 2005, p.881-892.

BUCHET, C. Consecuencias y enseñanzas para las marinas europeas de las operaciones navales llevados a cabo en el Caribe (1689-1713), Ibero-American Institute of Maritime Studies, París, 1999, p. 5.

BUENO, P. E. P. M. La política naval en el Atlántico, 1700-1715, Sevilla, Escuela de Estudios Hispanoamericanos, 1982, p.405.

GARCÍA, L. N. América en el siglo XVIII. Los primeros Borbones, Madrid, Rialp, 1989, p. 212.

GARCÍA, L. N. La política indiana. Historia General de España y América, Madrid, Rialp, 1983, v. XI-1, p.7.

GOODMAN, D. El poderío naval español. Historia de la Armada española del siglo XVII, Madrid, península, 2001.

HAHN, R. L'enseignement scientifique des gardes de la Marine au XVIIIe) siècle, In: TATON, R. (Ed.), Enseignement et diffusion des sciences en France au dix-huitieme siècle, París, Herman n, 1964, p.547.

INGLIS, G. D. The Spanish Naval Shipyard at Havana in the eighteenth century, New Aspects of Naval History, Baltimore, The Nautical and Aviation Publishing company of America, 1985, p.48.

LAFUENTE, A.; PESET, J.L. "Militarización de las actividades científicas en la España ilustrada (1726-1754)", J.L. Peset et al., La Ciencia moderna y el nuevo mundo, Madrid, C.S.I.C., 1985, p. 127-147.

LAFUENTE, A.; SELLÉS, M. A. El Observatorio de Cádiz (1753-1831), Madrid, Instituto de Historia y Cultura Naval, 1988.

LAFUENTE, A.; SELLÉS, M. A. El proceso de institucionalización de la Academia de Guardiamarinas de Cádiz. (1717-1748). Actas del III Congreso de la Sociedad Española de Historia de las Ciencias, San Sebastián- Zaragoza, Sociedad Española de Historia de las Ciencias, v.3 p.153-175, 1986. 
LÓPEZ, C. La teoría económica que fundamentó la política colonial americana de la corona española en el siglo XVIII, en Brocar, 29, 2005, p.96.

MARRERO, L. Cuba: Economía y sociedad, Madrid, Playor, 1972, v. 11, p.4.

MASSIEU, A. B. El Real astillero de Coatzacoalcos (1720-1735). Anuario de Estudios Hispano Americanos, XV, Sevilla, 1958, p.373.

MERINO, J. P. La armada en el siglo XVIII. Las Fuerzas Armadas Españolas: Historia institucional y social, Vol. II, Madrid, Alambra, 1981.

MESSEGUÉ, R. ¿Existió un poder naval hispánico? La reciente historiografía sobre la marina en tiempos de los Habsburgo (1516-1659). Revista de Historia Naval, n. 91, p.1-15, 1999.

NAVARRO, L. América en el siglo XVIII. Los primeros Borbones, Madrid, Rialp, 1989, p.119.

O’DONNELL, H. La marina durante el primer reinado de Felipe V (1700-1724). La Guerra de Sucesión en España y América: X Jornadas Nacionales de Historia Militar, Sevilla, Deimos, 2000, p.446.

OZANAM, D. La política exterior de España en tiempo de Felipe V y de Fernando VI. Historia de España, dirigida por Ramón Menéndez Pidal, Vol. XXIX, La época de los primeros borbones: La nueva monarquía y su posición en Europa (1700-1759), Madrid, Espasa Calpe, 1981, p. 457.

SOlANA, A. C. La Casa de la Contratación y la Intendencia General de la Marina en Cádiz, 1717-1730, Cádiz, Universidad de Cádiz, 1996, p.66.

TATO, J.F. G. "La enseñanza naval en España". Revista General de Marina, n.83, p.605-627, 1918.

TATO, J. F. G. "La enseñanza naval en España". Revista General de Marina; n.84, p. 49-64, 1919.

TATO, J. F. G. "La enseñanza naval en España". Revista General de Marina; n.84, p.179-196, 1919

TOMÁS, D. A. P. Los orígenes del Ministerio de Marina. La Secretaría de Estado y del Despacho de Marina, 1714-1808, Madrid, Instituto de Historia y Cultura Naval, 1998, p.389.

UZTÁRIZ, J. Theórica y práctica de Comercio y Marina, Madrid, edición fascímil, 1968, p.216217.

VV.AA, El buque en la Armada Española, Madrid, Museo Naval, 1981, p.415.

Recebido em: 27/02/2011

Aprovado em: 09/05/2011 